\title{
Threat or Treat for Tourism Organizations? \\ The Copenhagen Zoo Social Media Storm
}

\begin{abstract}
Social media have emerged as a game changer for tourism by empowering consumers to collectively approve or oppose organizational behaviors. When consumers rise against organizations, social media storms (SMSs) can be an outcome. This research proposes a conceptual framework to help tourism organizations understand SMSs and to guide more effective decision making. Contextualized by a case study of the Copenhagen Zoo, it is shown how and why SMSs are an expression of negative consumer empowerment that brings challenges as well as opportunities. As demonstrated, an SMS can lead to a helix for value creation for the organization, consumers, and society.
\end{abstract}

\section{KEYWORDS}

Social media storm (SMS); tourist attraction branding; consumer empowerment; negative customer emotions; marketing management; Copenhagen Zoo

\section{1 | INTRODUCTION}

Social media have profoundly impacted tourism and marketing (Leung, Law, van Hoof, \& Buhalis, 2013) by fundamentally changing the way organizations interact with customers. Booking sites have diminished the role of travel agents as consumers can plan their holidays more expediently, conveniently, and cheaply. Social media and sites based on customer reviews, like TripAdvisor, have gained momentum (Oriade \& Robinson, 2019). Tourism organizations may benefit from their global range, but Wee (2017) warns organizations and researchers not to ignore the role of social media as they enable consumers to become critics in their own rights. Though social media communication strongly impacts tourism firms and tourist decision-making (Moro and Rita, 2018), it is scarcely investigated in tourism research. 
This research aims to fill this void by showing why consumer empowerment in the tourism sector is not only realized through online consumer-centric marketing (Niininen, Buhalis, \& March, 2007), but also by openly sharing opinions, attitudes, and emotions towards service providers. While consumers embrace the empowerment, organizations struggle to manage the process (Shankar, Cherrier \& Caniford, 2006). In an increasing number of cases, negative emotions having retaliatory intent and anger (Grégoire \& Fisher, 2008) accumulate on social media, and are being referred to as social media storms (SMSs). An SMS refers to a sudden and explosive social media dissemination of negative consumer emotion towards an organization (Pfeffer, Zorbach, \& Carley, 2014). Consumer empowerment is defined as a state of mind, often accompanied by a physical act, which enables consumers to push through their needs, wants, and demands with other individuals or organizations in the marketplace (Pires, Stanton, \& Rita 2006; Wright, Newman, \& Dennis, 2006).

The complex relationships among social media, negative customer emotion and empowerment remain poorly understood and under-researched in the context of tourism (Neuhofer, Buhalis, \& Ladkin, 2014). Tourism research explaining the determinants of positive emotion and emotional effects on consumer behavior (Jani \& Han, 2013) is not accounting for the constructive potential of SMSs for strengthening relationships between parties (Romani et al., 2013). Having identified the central research gaps, this research unravels an SMS as an expression of negative consumer empowerment emerging from negative emotions, in particular anger, in the context of tourism by addressing how and why SMSs can empower tourism organizations. To understand SMSs as an empowerment phenomenon, the concept of consumer empowerment is revisited and the role of emotion in tourism research is investigated, arguing that negative emotions deserve recognition as they influence decisions to purchase travel, hospitality, tourism and leisure services (e.g., Chuang, 
2007; Larsen, Brun, \& Øgaard, 2009). Also, tourists' subjective experiences and emotional reactions are fundamental determinants of post-consumption behaviors (Gnoth, 1997), leaving the hospitality, travel, and tourism sectors particularly vulnerable to SMSs.

Negative emotions materialize in various forms but are mainly viewed as a reaction to unmet service expectations (Su, Hsu, \& Marshall, 2014). When organizations fail to keep their promises or behave in ways that are not applaudable, negative retaliatory emotions such as anger trigger social media-driven networked consumer actions spanning from individual complaints to collective exposure, criticism, parody, and even global riots manifested by SMSs. The exponentiality of such actions requires new, rather than traditional, management techniques because traditional consumer anger management tends to compromise rather than empower brands. Organizations can utilize the huge attention to initiate core value discussions of larger societal relevance as part of the service experience, but they must review assumptions that empowerment is like a seesaw swinging in favor of either the consumer or the organization and that negative emotions are a threat. Research should "incorporate diverse views on consumer behavior and its antecedents beyond the acquisition of knowledge as an empowerment mechanism” (Angulo-Ruiz \& Pergelova, 2014, p. 6).

The presentation of this research is organized as follows. First, a literature review presents three constructs in the context of the tourism sector: online and social media, the rise of consumer empowerment, and the role of negative emotions. Then, why organizations assess negative consumer empowerment as a challenge (threat) or as an opportunity (treat) are discussed. Next, the case study presentation of the Copenhagen Zoo contextualizes and analyzes the notion of viewing an SMS as an opportunity for an organization in the tourism sector, followed by findings and discussion sections. Finally, the implications for tourism marketing and management are explained. 


\section{2 | LITERATURE REVIEW}

Three main constructs of this research frame the literature review, namely social media, consumer empowerment, and negative emotions. These streams of thought provide insight into how and why SMSs can empower consumers, tourism service providers, and society, i.e., satisfying triple-bottom-line requirements by integrating the People, Profit, and Planet dimensions (Elkington, 2018). 'People' refers to building human capital through fair and beneficial business practices for internal and external stakeholders. 'Planet' refers to protecting natural resources through sustainable environmental practices. 'Profit' refers to the monetary value and actual economic impact that an organization generates (and not just internal profits).

\section{1 | Online and social media research}

Previous research has explored the role of IT for generating customer intelligence and involvement of customers in the development of tourism services (Sigala, 2012), the role of Google Trends data in forecasting tourism demand (Önder, 2017), the factors that influence the adoption of the Internet (Abou-Shouk, Lim, \& Megicks, 2013), the use of mobile technology by travel agencies (Lin, 2017), and knowledge sharing in tourism-related review and social networking sites (Okazaki, Andreu, \& Campo, 2017; Oriade \& Robinson, 2019).

Social media profoundly impact global tourism, travel, and hospitality brands, so these brands must consider the powerful effects of e-Word-of-Mouth (eWOM) due to immediacy, higher reach, and accessibility (Moro \& Rita, 2018). Tourism, travel and hospitality organizations were early adopters of customer relationship management (CRM), which led to a far-reaching assumption that most types of business-customer interactions are relational (Senders, Govers, \& Neuts, 2013) and should be built on meeting consumer expectations and positive branding. Consequently, organizations expect to respond to customer complaints in a 
manner that re-establishes the positive customer relationship (Tyrrell \& Woods, 2004), which explains why this stream of research frames an SMS as a threat.

Such was the case of the Rockhampton Tourism campaign ${ }^{1}$ in Australia. It caused an SMS in 2018 after excluding local indigenous people in the promotion, leading to local authorities apologizing and the withdrawal of the campaign. In 2018, an SMS in Saudi Arabia about how Saudi tourists are perceived abroad sparked heated discussions ${ }^{2}$. But social media can also play a significant role in improving customer service and communication, as EgyptAir did in 2013 during a politically unstable period that impacted tourism in Egypt ${ }^{3}$.

Tourism, being an information-intensive sector, relies heavily on cross-channel communications (Zhong, Leung, Law, Wu, \& Shao, 2014). Travelers review airlines, destinations, hotels, entertainment and activities which impacts their buying decisions (Leung et al., 2013; Litvin, Goldsmith, \& Pan, 2008). Cognitive, affective, and evaluative components of customer brand identification interact with each other in realizing positive and negative eWOM (So, Wu, Xiong, \& King, 2017; Su et al., 2014). Ku (2014) shed light on the dynamics within online travel communities and explored factors such as social identification that affect the sharing of tacit knowledge. Nusair, Bilgihan, and Okumus (2013) found that Gen Y travelers' use of social media is driven by innovativeness, desire to share information, and perceived utility, while their interactions are predictors of trust and loyalty. Tourism and travel organizations try to eliminate threatening power imbalances that occur in social media to regain loyalty as did American Airlines and JetBlue 4 in handling flight issues by providing a "human touch" to avoid frustrating experiences.

Nevertheless, paradigmatic changes in business processes and service standards towards a neo-tourism era are creating new possibilities for marketing innovations as well as

\footnotetext{
${ }^{1}$ https://www.lostateminor.com/2018/06/18/aussie-tourism-campaign-causing-social-media-storm-white/

${ }^{2} \mathrm{http}: / /$ saudigazette.com.sa/article/139377/Saudi-tourists-behavior-stirs-social-media-storm

${ }^{3} \mathrm{https}$ ///www.thinkdigital.travel/opinion/calm-in-a-storm-egyptairs-approach-to-social-media/

${ }^{4}$ https://www.entrepreneur.com/article/286408
} 
changing consumer expectations (Gretzel, Fesenmaier, \& O’Leary, 2006; Neuhofer et al., 2014). This phenomenon means growing social media influence as a way for organizations to create transparency and ease consumer decision-making, demonstrate sustainable practices, as well as satisfying individual needs (Rydén, Ringberg, \& Wilke, 2015). Thus, how power is perceived and distributed among consumers and marketers affects how consumers behave (Labrecque et al., 2013). Academic tourism research is "being largely outrun by the reality occurring in the business world where social media has been strongly adopted by firms" (Moro and Rita, 2018, p. 358). which calls for revision of existing research and practices.

\subsection{The rise of consumer empowerment in tourism}

The tourism marketing literature is now increasingly acknowledging the fact that consumers actively co-create value (Rihova, Buhalis, Moital, \& Gouthro, 2015). Consumer-generated content can serve as raw data for analysis by identifying areas of competitive advantage, needs for service improvements, and opportunities for responses to customer articulations (Munzel \& Kunz, 2013). Prior research has noted that within online travel communities, individual behaviors benefit the members of those communities, "with the expectation of selfenhancement through a boost in both personal and collective self-esteem" (Ku, 2014, p. 33). IT adoption is enabling consumers to seek better value propositions leading to an uncontrolled growth of consumer empowerment (Deighton \& Kornfeld, 2009). Consumer empowerment takes different forms, but in general, it defines a fundamental change in the business environment: "democratization of technology", "knowledge transparency" and "customer empowerment" reflecting consumers' enhanced ability to access, understand and share information (Pires, Stanton, \& Rita, 2006). Transforming "information scarcity" into "transparency" has huge implications for the design of market communication strategies, requiring consumer-centric approaches. 
Social media have transformed consumers from passive recipients to active players by providing information, pluralism of choices, networking, and direct organization access (Rydén et al., 2015). In an SMS context, consumer empowerment refers to a process (i.e., social media empower people to gain control over issues that concern them) and an outcome (i.e., individuals feel a sense of control, understand their sociopolitical environment, and become active in efforts to exert control) (Wright, Newman, \& Dennis, 2006). Moreover, consumer empowerment is viewed from a consumer perspective (i.e., consumers deciding to openly voice and share opinions and emotions about particular behaviors in the market - alone or with others) and from a organizational perspective, (i.e., crowds articulating beliefs about them and/or pressuring with demands for changes in actions).

Pires, Stanton, and Rita (2006) support the proposition that marketing strategy rests on a control premise but talk of a need to regain control over the marketing process by managing the technological empowerment of consumers. They state that loyalty is earned when organizations can empower customers, who then lack further interest or motivation in searching for alternative suppliers. Consumers are adapting well to the new paradigm, while organizations appear to be unsure of how to manage the empowerment process (Shankar et al., 2006). Thus, an SMS is a nightmare to managers who seek to achieve brand protection rather than brand building (Fournier \& Avery, 2011).

Many marketing practices still rest on a business-centric control premise, meaning that organizations are employing strategies to reduce consumer power (Pires et al., 2006). Power is a cardinal component of social systems and thus a key human concern that constantly influences behavior (Labrecque et al., 2013). Following Denegri-Knott, Zwick, and Schroeder (2006), the relationship between power and knowledge is crucial to understanding negative consumer empowerment because consumers mobilize discursive 
strategies to determine what is right, true, and important knowledge and what actions can be undertaken in any particular field of action (i.e., the market). Here, social media are used in bringing power relations into being and in influencing consumers and organizations through SMSs. For example, this research highlights the scientific vs. sentimental discourse that affected a zoo-consumer relationship and in what ways social media intervened in how they interacted with - and reacted to - each other.

\subsection{Anger as the driver of negative consumer empowerment}

Negative consumer empowerment refers to the process of letting negative emotions motivate and drive individual and collective capacity to choose and transform choices into desired behaviors and results. Many consumers think of and act on the impact of their choices on wider society and such awareness is regarded as a legitimate form of empowerment. Consumers influence the brands they perceive as non-ethical by exercising actions such as boycotting and rewarding those that are perceived as ethical (i.e., positive buying). Brands face the challenging reality of public complaining that involves customers who alert the public about failures: "Online complaining could be interpreted as a form of divorce that is announced publicly.” (Grégoire, Tripp, \& Legoux, 2009, p. 27). Truong and Simmons (2010) urge organizations to creatively and effectively tap into the communities of empowered consumers as they enable further sharing of opinions and experiences. Labrecque et al. (2013) emphasize that those communities are stronger than empowered individuals, which adds to the dynamics of the consumer empowerment construct.

Showing negative emotions like anger empowers people in terms of correcting social injustices and abnormalities. Prior research on inter-group conflict finds anger to be a central and prevalent emotion (Bar-Tal, 2007, Halperin \& Gross, 2010). It is driven by the attribution of others' accountability (Kuppens et al., 2003), motivation to act, expressing opposition 
(Carver \& Harmon-Jones, 2009); engaging in risky behavior, and correcting perceived wrongdoing. These characteristics make anger the most relevant emotion in an SMS context. Angry consumers, and the attention an organization must pay to deal with them to recover, is what links anger and empowerment. A negative experience can evoke anger, which is a strong driver of tourist behavior (Pavesi, Gartner, \& Denizci-Guillet, 2016). Anger represents reactions to moral violations and provides a link between moral standards and judgements (Romani, Grappi, \& Bagozzi, 2013). Gershoff, Mukherjee, and Mukhopadhyay (2007) support Tolstoy's view that there are few ways to love, but many ways to hate. "Hated products tend to have relatively unique reasons for being hated" (p. 505), which further complicates the consumer anger issue.

Anger is found to be one of the prime causes of hatred. Research has considered hate to be a form of generalized anger (Bernier \& Dozier, 2002) and problem anger (PascualLeone et al., 2013). Hate and anger thus seem to be closely related in spite of having some appraisal-based differences (e.g., Halperin, Russell, Dweck \& Gross, 2011, Frischer et al., 2018, Royzman et al., 2005). Broken promises, unfair treatment, and expressed hostility cause consumer anger (Funches, 2011). If anger remains unaddressed by organizations, contempt can develop, leading to severe consequences for the brand (Fournier \& Avery, 2011). Unlike contempt, anger is also a constructive emotion. Consumer anger, although often interpreted as attacking behavior, may actually improve the relationship between the two parties (Romani et al., 2013), expressed mainly by consumers who want to maintain relationships with organizations that improve their wrongdoings, which is likely to result in actions that allow reconciliation. This makes anger an important and promising issue for organizations to comprehend (Wang, Weaver, \& Kwek, 2016). According to Huang, Scott, Ding, and Cheng (2012, p. 91) "little attention has been paid in the tourism literature to the influence of mood on service evaluation and judgment" even though "mood levels have been 
found to vary across stages of the tourist experience" (Nawijn, 2010, cited in Huang et al., 2012, p. 91). Therefore, there is much room for exploration of negative consumer sentiment, its interpretation by firms and impact in the tourism context.

In summary, the review reveals relationships between two central drivers of SMSs as negative consumer empowerment: social media and negative emotions. Emotions have vital social functions and consequences as they influence the behavior of the people who experience them, as well as the behavior of those who perceive them. This demonstrates that the empowered consumer is quickly and radically altering fundamental concepts of tourism brand management. Assessment of the complex interplay between affect, reason, and action is essential for SMS management.

\section{3 | NEGATIVE CONSUMER EMPOWERMENT: THREAT OR TREAT?}

Organizations usually assess an SMS as either a challenge (Threat) or opportunity (Treat). An SMS triggers a feeling state, including automatic reliance on rapid affective responses (affect heuristics) (Slovic, Finucane, Peters, \& MacGregor, 2004), demarcating a positive or negative quality of a stimulus as "threat or treat". In some cases, SMSs yield negative reactions and consequences for organizations (Shankar et al., 2006), which is why they should address SMSs through strategic and tactical consumer interaction to secure wanted results (empowerment) and to prevent unwanted results (bad publicity).

Rauschnabel, Kammerlander, and Ivens (2016) provided insight into the nature of SMSs by exploring their antecedents, characteristics, and consequences. To their surprise, they found that an SMS could result in positive consequences for the brand by improving feedback, gaining sympathy and supporters. The mechanism supporting a constructive approach to an SMS is grounded on the fact that negative emotions tend to leave strong affective traces in episodic memory that allow people to draw on experiences and call up past 
events and emotions, giving them the ability to imagine and anticipate the future (Funches, 2011). Destructive patterns are more predictive, which helps organizations to observe and react towards threatening emotions by knowing their impact and what actions they need to take to gain an empowering outcome. For example, educating visitors and communicating the reasons for management actions is seen as an effective way to gain customer support in wildlife tourism experiences (Curtin, 2010).

Many organizations still do not grasp the nature of empowered consumers so endeavors to connect may seem inauthentic and intrusive: "At best, its role is to provoke conversation among consumers, and at worst it becomes the enemy, attacked with invective or parody" (Deighton \& Kornfeld, 2009, p. 4). The fact that most tourism marketers are not embracing SMSs is because consumer empowerment is often misunderstood at its foundation. Truong and Simmons (2010) describe empowerment as a challenge, which marketers mainly decide to fight back against or play along with to recover the relationship with the consumer by offering apologies, concessions, influence, or allowances (Bernoff \& Schadler, 2010). Others more appropriately address empowerment through enhancing efficiency, differentiation, cooperation, socialization, dialog, transparency, and truth-telling (Rydén et al., 2015).

These factors determine the outcome of this assessment as "win-lose" where either the organization or the consumer is empowered. It may also result in a "triple-win" situation where the consumer, organization, and society are mutually empowered by the SMS as it sparks the necessary information literacy and knowledge to recognize a general need for "higher-order thinking and acting". Such acquisition of strategic thinking attached to social and technical abilities becomes more critical not only for employees of the tourism, travel and hospitality sector, but also in general because sustainable action requires a knowledgeable society that can work collaboratively with individual and immediate emotions, and perspectives. People's immediate emotional responses may lead to more 
reflective reasoning about the situation, which can be the path to responsible and sustainable actions, as in the case study presented next. Figure 1 depicts this applied conceptualization.

[Figure 1 near here]

In the conceptual framework presented in Figure 1, the SMS as a central construct stems from two main drivers: the proliferation of social media, and the emergence of negative emotions in consumer-brand interactions. An SMS can have various facets, as identified in previous research (e.g., anger directed towards an organization, or generalized anger towards a theme). Once an SMS emerges, there are two opposing perspectives and possible reactions to it: attempt to control it (the most common approach; organization-centered) or embracing empowered consumers (recently identified alternative approach; consumer-centered).

Considering an SMS as a threat leads to organizational control of an SMS usually resulting in a win-lose scenario (either the organization or consumers are "defeated" in the conflict).

Considering an SMS as an opportunity leads to embracing empowered consumers and allows for a win-win-win scenario (for all parties involved: tourists, organizations, and society). Changing the perspective requires reframing of the approach to an SMS from the organization's side, which enables a more responsible approach to all stakeholders involved (tourists, society, and organizations).

\section{4 | A "WILD" CASE STUDY}

A case study of an attraction (Deszczynski, 2017; Tsaur, Chiu \& Wang, 2007) is elaborated to provide rich insights into the workings of a tourism organization for theory building (Fiss, 2013). Case studies in tourism have provided insights in destination management situations, e.g., destination image of protected areas (Rosa, Carvalhinho, \& Soares, 2018), effect of 
information source on country and destination image (Alvarez \& Campo, 2011), and stage of industry development on tourist expenditures and attraction toward destinations (Catlin, Jones, Norman, \& Wood, 2010). Data were collected within a zoo to understand the dynamics present (Eisenhardt, 1989) for uniquely increasing brand value during an SMS and to preserve the integrity of the case and understand it as a particular configuration of features embedded in a specific context and time. The case presented meets Pettigrew's (1990) criteria for selection of empirical sites for case studies: (1) extreme situations, critical incidents, and social dramas (the SMS turned into a global drama and consumers considered it an extreme situation, although animals are euthanized daily); (2) polar types that allow for stronger contrasts (there were defenders as well as opposers); and (3) organizations with a relatively high experience levels of the phenomenon under study (management seemed to understand, at a deeper level, what was going on).

The Copenhagen Zoo is one of Denmark's largest and most important tourist attractions with an increasing number of visitors reaching $1,172,439$ in $2017^{5}$, visioning to become known internationally as a brand of high ethical standards and respected as an active nature conservation organization by using innovative communication, education and displays. On tourism websites such as VisitDenmark ${ }^{6}$ and VisitCopenhagen ${ }^{7}$ it is included in the top ten most popular attractions. According to Zhang (2012, p. 1137) "different attractions normally will attract different types of visitors" and zoos are among the most popular family attractions in Denmark. This research combined evidence from multiple sources: in-depth interviews and other secondary data, such as newspaper articles, websites, annual reports of the Zoo, and a sentiment analysis of the SMS (Zimmerman, Chen, Hart, \& Vatrapu, 2014).

\footnotetext{
${ }^{5}$ https://www.zoo.dk/files/AArsberetning_2017.pdf

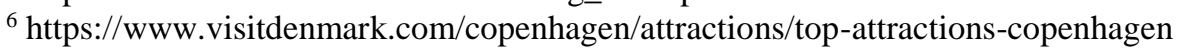

${ }^{7}$ https://www.visitcopenhagen.com/copenhagen/sightseeing/top-30-attractions
} 
Although the case study as developed and reported relies on one in-depth interview, the use of complementary secondary and Zoo data effectively shows how the management of a large tourist attraction analyzed the situation, identified the game-changing potential of the SMS, and generated positive brand awareness from negative consumer empowerment.

\section{1 | Marius - the trigger of the SMS}

In February 2014, the management took a vital decision to euthanize an 18-month old male giraffe, Marius, despite massive protests. It is a common practice for zoos to manage their animal populations to ensure they remain healthy and Copenhagen Zoo typically puts down 20-30 animals a year. The Zoo's Scientific Director had received death threats but would not alter his decision ${ }^{8}$. He stated that "Giraffes today breed very well, and when they do you have to choose and make sure the ones you keep are the ones with the best genes".

The euthanasia took place in agreement with the European Breeding Program as a transfer to another zoo would cause inbreeding. Visitors, including children, witnessed the post-mortem examination for educational purposes while vets explained and educated them. The remains ended up as lion food and were used for research. This event was announced in advance and knowledge of this euthanasia quickly spread across conventional and social media and since people relate to giraffes in an affectionate way ${ }^{10}$ it led to massive global protests and mourning ${ }^{11}$. An SMS developed fast and reactions beyond the Danish borders were not only larger in volume; they were also stronger in negative sentiment, and primarily expressed on Twitter ( $75 \%$ of the total online conversation), being a less popular medium in Denmark (Zimmerman et al., 2014). The Marius case even got its own Wikipedia page ${ }^{12}$.

\footnotetext{
${ }^{8}$ https://www.bbc.com/news/world-europe-26098935

${ }^{9}$ Ibid.

${ }^{10} \mathrm{https}: / /$ www.theguardian.com/commentisfree/2014/feb/10/giraffe-killed-fuss-human-beings-animals-marius

${ }^{11} \mathrm{http} / / /$ timzimmermann.com/2014/02/12/marius-the-giraffe-is-every-zoo-animal/

${ }^{12}$ https://en.wikipedia.org/wiki/Marius_(giraffe)
} 


\section{2 | Analysis}

The case focuses on a private Danish B2C tourism attraction organization. The sampling unit was a senior level manager possessing a high level of expertise and strategic acumen, who steered through an SMS in a way that strengthened the business and increased its brand value. The Director of Copenhagen Zoo was interviewed for 90 minutes using an interview guide of open-ended questions that was developed based on theoretical findings.

Data were coded to identify views on customer emotions, social media, and the outcome of the SMS. A theory-based coding scheme was developed. From the reviews, words and concepts were identified and clustered, which helped develop a common frame of reference of what to look for, how to uncover the complex tacit understandings of the manager, and how to capture the strategic moves during the SMS event that the interviewee mentioned. Following the qualitative research methodology of Miles and Huberman (1994), the scheme developed inductively during the interview period, adding novel codes in cases where the interviewee mentioned new aspects relevant for the analysis. Therefore, the identification and analysis substantiated the conceptual framework (Figure 1) and the proposition of why and when an SMS can be regarded as a tourism marketing and branding "treat" (Eisenhardt, 1989). The findings inductively strengthened the framework and enriched the constructs by bringing new insights, which aligned with central findings in the literature on negative emotions expressed and shared on social media (Jalonen, 2014).

In order to account for the reliability of the coding procedure, two independent coders collaborated, following a blind coding procedure. Disagreements were addressed by the two coders debating and jointly resolving discrepancies (Krippendorff, 2004). Regarding the validity of the coding frame, the inductive method of coding is one way to ensure that the coding frame captures what it sets out to capture (Schreier, 2012). Face validity was 
enhanced as a pilot coding procedure was part of the cyclic coding process, which improved the accuracy of the coding frame and the level of abstraction employed to summarize and reduce the material to keep it at a medium level (Schreier, 2012).

The main concepts expressed within Figure 1 structured the findings as follows:

(1) Negative emotion and consumer empowerment identify the participants in the SMS and their emotional responses and foci, e.g., the person, the organization, the event, or the general conditions for wild animals, and further analyze their reasoning and motivation.

(2) Social media and SMSs refer to the platforms used for negative emotion outbursts, and the dynamics of sharing negative emotions.

(3) Outcome identifies the dynamics of handling the SMS from a managerial perspective, revealing the aftermath of the SMS and key learning points for organizations involved.

\section{5 | FINDINGS}

\section{1 | Negative consumer empowerment}

The cultural differences in wildlife practices surfaced on social media. The Director of the Association of Zoos and Aquariums' Wildlife Contraception Center at the St. Louis Zoo, stated that euthanasia is not a comfortable fit for Americans who use contraception instead ${ }^{13}$ : “On an emotional level, I can't imagine doing it and I can't imagine our culture accepting it." ${ }^{14}$ A "Close the Danish Zoo" site quickly got more than 15,000 followers, calling the Zoo "barbarians" and "murderers." Mainstream media brought the story, which sparked a strong global reaction, e.g., with the science correspondent, Virginia Morel, saying: "He should never have died so young and at the hands of his caretakers... the very ones who should have

\footnotetext{
${ }^{13}$ https://www.huffingtonpost.com/nancy-graham-holm/a-different-philosophy-a_b_4803229.html?guccounter=1

${ }_{14}$ Ibid.
} 
done all they could to protect him". 15

Regarding anger in public opinion formation, there were notable differences between Danish and global reactions. In fact, the SMS did not represent the voice of loyal local or potential customers. Subsequent text comparison of postings and articles in social media, as well as mainstream Danish and English-speaking media, illustrated why the SMS did not impact the number of visitors: Zimmerman et al. (2014) combined different data collection methods of manual and automatic sentiment analyses, text mining (word frequency), social media analytics, and online media netnography (Facebook and Twitter) to show the stark contrast between the much more intense and emotional international discourse and the discourse in Danish media, as evidenced by the differences in volume, sentiment, and topics in English vs. Danish data. For example, Twitter posts counted $75 \%$ of the total online conversation, and Facebook only $20.8 \%$. Of the $75 \%$, many of the posts were retweets, echoing the negative sentiment rather than reflecting the emotional state of the person retweeting (Zimmerman et al., 2014).

In Denmark, Facebook is preferred to Twitter as opposed to the US and United Kingdom. Subjectivity and negativity were higher on Facebook in the English language than in the Danish language. Not only did the channel amplitude differ; so also did the nature of the conversation. The intended Twitter audience was mostly public in nature, so the intended signal was different to that of Facebook, which is more friend-based and private. Moreover, the original explanation from the Zoo also received unprecedented levels of likes, especially by visitors (Zimmerman et al., 2014). This may partly explain why the SMS was a treat, not a threat. The Director considered Danes as the (potential) customer base, not the international crowd, who escalated the SMS. The Director emphasized a specific cultural aspect that

\footnotetext{
${ }^{15}$ https://guce.oath.com/collectConsent?brandType=nonEu\&.done=https $\% 3 \mathrm{~A} \% 2 \mathrm{~F} \% 2 \mathrm{Fwww}$. huffingtonpost.com $\% 2$ Fnancy-graham-holm\%2Fa-different-philosophy-a_b_4803229.html\%3Fguccounter\%3D1\&sessionId=3_cc-session_df1dab69-e6bd-4c08-9f1acd4cdc456404\&lang=en-US\&inline $=$ false
} 
influenced the Danish posts: "A lot of Danes had very pragmatic reactions. The

Scandinavian approach to animal care is much more pragmatic." This opinion was shared in the management team.

The Zoo did not base their decisions or reactions on visitor/non-visitor segmentation and analysis. They decided based on what felt right in the particular situation, reflecting their mission and corporate identity. The management response was pragmatic, continuously based on their own methods, theories, and standards of evaluation. Pragmatic culture emphasizes process, method, correction, and change. By insisting on this type of process, the practices remain open to correction by the community (Pellow, Schnaiberg \& Weinberg, 1995).

This finding supports that local reactions may have a direct effect on profit, but the risk is minor as long as loyal customers keep visiting and defending the brand. Jalonen (2014) identifies altruism as a motivation for people to vent through social media and cultural differences in social media use as being important during outbursts of anger. Identifying the relevance of SMS participants to the organization (visitors vs. non-visitors), their characteristics (e.g., demographics and culture) and motivations (e.g., venting for themselves or for altruism) emerged as important elements in understanding and managing the SMS.

The anger aroused by the incident seemed to empower consumers through a collective voice and movement. To the Director, the anger espoused was not deep-seated, but a spontaneous emotional arousal enabled by social media: "I think it is sad that people are willing to post things on social media that they would never say if they were in front of the person". Referring to the concept of tribal identity, becoming part of the "Against the Zoo" movement stimulated a belongingness need and a convenient opportunity to utter frustration of how modern lifestyle leads to alienation and detachment from nature. The Director stated:

"This case was a bomb waiting to go off... I think, people thought 'now I have a chance to engage myself in something that I can prevent'. Some people made it a 
hobby for a short while to prevent this."

The SMS became an online echo chamber as the participants self-righteously pursued a group identity echoing each other. It was vital to figure out how to break this bias accelerator and enable some learning to take place. In most cases, the SMS requires a trigger, which could be an incident or a "dormant" dissatisfaction that waits to be "awakened" to accumulate. In this case, the Director recognized anger as a constructive negative emotion, stating that most of the reactions were focused on changing organizations' behavior for the better.

\section{2 | Social media as a driver of SMSs}

Two major insights emerged: First, the social media type plays an important role in accentuating sentiment in posts. Second, SMSs are further fueled by traditional media coverage. The Director acknowledged how Twitter played an important role in negative sentiment outbursts while traditional media covered the incidents heavily:

"The story took off on Twitter. The problem with Twitter, or the balance with Twitter, is that the statements have to be more extreme if you have 140 characters to make a point... social media work very well for people, who have a lot of anger. It is an easy way to take part: you can click on a button; you can live in a suburb of Houston and really be angry and send it off somewhere else in the world by the click on a button. You can take part, it's free, and you don't have to be there, you don't have to stand up for it, you don't have to face people."

He emphasized the empowerment and transparency effect of social media as a mirror for the organization that helps them adhere to ethical practices:

"That is the positive about social media: you can't get away with stuff, so you better start cleaning up your own stuff, because it will come out."

The managerial decisions prioritized pragmatism over sentimentality. To manage the 
Zoo authentically, they kept meeting the public anger with a scientific and animal ethical discourse rather than accommodating the criticism and demands. The Director reframed the agenda from a Marius issue to a wildlife welfare issue and scoped it out, opposing against an inappropriate "civilized" culture of meat-eaters and the hypocrisy that follows in the protest of killing animals.

"... I think, it is a risk that people are getting so detached from nature that they get a totally unrealistic view on how we interact with nature and what we eat and why we do it. It is our job to slow down that detachment from nature".

People's reactions were identified as "the result of a whole culture" getting it wrong. Seen from a traditional crisis communication perspective, this reframing would appear to be a convincing scientific response legitimating professional action. But strategic communication and smart rhetoric is not sufficient to utilize the forces of an SMS. Rather, it demands full transparency of ethical business practices and following with authentic communication. The future of tourism marketing will be characterized by an increased use of social media, coupled with intensity of visitors' emotional involvement; not in the brands necessarily, but in how the managers run their businesses and act. The findings underscore the urgency for tourism organizations to understand the drivers of SMSs, to acknowledge negative consumer empowerment and to sense and seize this new type of extended experience factor.

\section{$5.3 \mid$ Perspective and outcome}

The management handled the SMS by not compromising their core values in their communications and their actions. They relied on a strong consensus of doing the right thing for wildlife. The assessment was clear: The Zoo takes best care of its brand by taking care of its animals, so no need to apologize about this incident despite the measurable negative reactions and advice to do so from marketing specialists. If the Zoo had followed the protests 
and kept the giraffe, the SMS may probably have calmed down faster, but the Zoo would then have been facing a tremendous problem of compromising their core values, ethical standards, and jeopardizing their brand. In the aftermath, the SMS sparked a global discussion in countries of different practices. The Director traveled the world to give talks and gained respect for the approach, as expressed by Naomi Rose, Animal Welfare Institute:

"So, while the Copenhagen Zoo may have been the least sensitive practitioner of this 'management' method, please do not direct your ire at the Zoo or its director. They were in fact the honest ones. ALL zoos - ALL ZOOS - do this to one extent or other."

The Zoo prioritized a high level of professionalism in wild-animal welfare rather than classical strategic communication. The Director stated that they were empowering people by adhering to those core values ${ }^{16}$, stressing that fear is the real enemy, because organizations tend to exaggerate the effects of crisis management. If the SMS becomes personal or hits the organization's core products or values, it is better to stay firm on the decision and to explain and communicate the reasoning: "We need to make sure that people understand how things work and how nature is. That is the whole purpose of being here, not just to show funny animals." Taking responsibility for educating people was anchored in the Zoo's mission and identity, knowing that it was risky. It is evident that people were already educated during the Marius case to suspending the threat in the next case:

“...looking back on it, we can see that we actually managed to raise the awareness of what zoos do around the world to an extent that not many experience in their lives... You can say that people got educated during the Marius case."

Soon after the incident, the Zoo euthanized four lions to prevent them from

\footnotetext{
${ }^{16}$ http://uk.zoo.dk/VisitZoo.aspx
} 
inbreeding and to allow for the arrival of a new male lion ${ }^{17}$. Interestingly, the international media pointed to the risk that these killings were undermining Danes' international image ${ }^{18}$, but the Danes kept a pragmatic stance: "We could see, during the lion case that came five weeks later that on Facebook people were explaining to each other why we were doing this". Though the SMS did not affect their sales negatively, the Zoo learned not to give human names to animals. The Annual Report of 2014 substantiates the findings:

"2014 will be remembered for the Giraffe case, where euthanizing a giraffe created immense media attention and a regular social media storm. We received much support from people and zoo colleagues and sparked a debate on euthanization practices. The social media storm strengthened the Zoo. Experienced by a subsequent euthanization of four lions shows that the incident enlightened people and that it pays off to be open, honest, and stay firm on your professionalism." 19 (Steffen Strade, Director)

\section{6 | DISCUSSION}

The Copenhagen Zoo was used as an exemplar case, showing best practice. Although one example does not provide enough basis for generalization, the analysis shows how an SMS can be regarded a 'treat' of increased attraction and brand value supported by transparency and adherence to the strategic pillars of identity, mission, and vision. People gained insights into the challenges of preserving wildlife in zoo cities and the Zoo engaged and opened up for a global discussion on society's view on and alienation with natural life in perfect alignment with the sustainable elements of neo-tourism. The SMS became an opportunity for value co-creation and for raising social awareness on an eco-issue, leading to a "triple-win"

\footnotetext{
${ }^{17} \mathrm{https} / / /$ www.nytimes.com/2014/03/27/world/europe/lion-killing-at-danish-zoo-provokes-fresh-outrage.html 18 Ibid.

${ }^{19}$ https://www.zoo.dk/files/AArsberetning_2014.pdf
} 
outcome for the organization, consumers, and society (the Zoo enhanced its integrity and scientific stance; the visitors were better educated about preserving wildlife in urban spaces; and society had a wake-up call about its alienation from nature). As many protests were spread by people who most likely would never visit the Zoo, the actions taken by this organization empowered its brand by putting zoo animal welfare on the agenda, while keeping the image of a transparent, educational experience brand. Can other tourism organizations and societies also gain from negative consumer empowerment? Yes, if they can turn the attention of consumers on raising/engaging issues, e.g., politically loaded issues like sustainability and global welfare, instead of clinging to "the consumer is always right" doctrine, which may disempower organizations or consumers in the long run. Voices of empowered visitors can lead to an improvement in the quality in tourism, but organizations often neglect renewal and development even though they should improve and develop their activities on a continual basis. If not, they are likely to fail (Hjalager, 2001).

\section{7 | CONCLUSION AND IMPLICATIONS FOR TOURISM MARKETING AND MANAGEMENT}

The success of the tourism sector is built on the central aspects addressed in this research: sensitivity towards consumer emotion, and the ability to make consumers feel empowered, through social media interaction. The scale of the power shift between marketers and consumers is large enough to create a structural change in business and marketing practices, bringing the need for a new understanding of the environment, new strategies and tactics (Pires et al., 2006). There is a unique opportunity for tourism organizations to become exemplar SMS managers. The contribution of this research is to provide those managers with a conceptual framework and empirical evidence of SMSs as a treat for discovering the potential and to develop their knowledge and practices. It is shown that the general view of 
the SMS as a "threat", in the form of unwanted bad publicity and loss of control, can be a "treat" providing opportunities for win-win-win outcomes for tourism organizations.

These findings offer important implications for future management of tourism brands. SMSs are an accelerating phenomenon and the probabilities for SMSs are higher in the tourism sector where services are offered globally and involve experiences, as anger can be easily shared on social media. The SMS may have negative or positive implications for a brand depending on the organization's understanding of anger, social media dynamics, and the management response. Thus, it is vital that managers in tourism adopt a positive orientation through the utilization of social media to survive and grow (Glavas, Pike, \& Mathews, 2014). The findings should encourage tourism organizations to utilize the dynamics of an SMS in a meaningful and constructive way by reframing the anger-evoking issue into a broader context of the common goal. This approach answers Truong and Simmon's (2010, p. 250) call: “marketing managers will need to be creative in how they respond effectively tapping into the empowerment and control that consumers now have and want in the digital world."

The constructive force of negative emotions is to demand actions for improving business practices (Romani et al., 2013). As empowerment requires socialization, organizations can adopt this knowledge by creating or sponsoring spaces for consumers to express themselves and influence decision-making to redirect activities and to avoid a destructive state of contempt (Jarvenpaa \& Tuunainen, 2013). Managers can design strategies that harness customer identification, create a sense of partnership, and empower consumers by letting them determine what they are interested in and how they wish to engage with organizations. Rydén et al. (2015) suggest that managers question the relevance of the "Promote \& Sell" approach, vested in a business-to-customers mental model, and explore alternative "Empower \& Engage" strategies based on a business-for-customers mental model. 
Though empowerment exceeds the "co-creation potential", it may backfire when not approached correctly. The main points are condensed into new routes for tourism marketing management and suggest new practices for tourism managers:

Understand the relevant factors for assessing the SMS (Figure 1). When organizations understand the SMS, it is easier to handle communication skillfully, even though it may go global and create headlines in distant places.

Revise the understanding of control in marketing management. Traditional approaches are ineffective with social media. Organizations must be open for experimental marketing management practices on social media. Management must reconsider how to increase attention, interest, understanding, and support.

Be open about core values and communicate. Transparency is central to win the respect of consumers, peers and media. Building a solid foundation and knowing what organizations stand for will become vital for succeeding in a neo-tourism era. A professional, scientific discourse can help people understand how things work.

When managers understand the power of SMSs, they can strengthen employee support, empower consumers and society, which is why this analysis emphasizes the need for future empowerment research to incorporate negative emotions. The SMS offers a reality test of how consumer-centric organizations act and reveal how well they understand customers' social media behavior and the effect on tourism branding and business reactions. A single case study has its limitations in terms of generalization. More studies are needed to cover the variety of tourism organizations to understand the practices and outcomes better and to learn more on the impacts of vision and emotion and whether other cases show similar effects. More research should take place on consumers who do not actively participate in the SMS but follow the SMS silently. These consumers may also be influenced in their buying behavior. Further studies on this "dark matter" of the SMS may grasp the potential effects. 


\section{REFERENCES}

Abou-Shouk, M., Lim, W. M., \& Megicks, P. (2013). Internet adoption by travel agents:

A case of Egypt. International Journal of Tourism Research, 15, 298-231.

Alvarez, M. D. \& Campo, S. (2011). Controllable versus uncontrollable information sources: Effects on the image of Turkey. International Journal of Tourism Research, 13(4), 310323.

Angulo-Ruiz, F., \& Pergelova, A. (2014). The definitions and constructs of consumer empowerment in marketing: A review and a way forward. Proceedings of the European Marketing Academy Conference, Valencia, Spain.

Bar-Tal, D. (2007). Socio-psychological foundations of intractable conflicts. American Behavioral Scientist, 50(11), 1430-1453.

Bernier, A., \& Dozier, M. (2002). Assessing adult attachment: Empirical sophistication and conceptual bases. Attachment \& Human Development, 4(2), 171-179.

Bernoff, J., \& Schadler, T. (2010). Empowered. Harvard Business Review, 88(7), 94-101.

Catlin, J., Jones, T., Norman, B., \& Wood, D. (2010). Consolidation in a wildlife tourism industry: The changing impact of whale shark tourist expenditure in the Ningaloo Coast region. International Journal of Tourism Research, 12(2), 134-148.

Chuang, S. C. (2007). Sadder but Wiser or Happier and Smarter? A Demonstration of Judgment and Decision Making. Journal of Psychology, 141(1), 63-76.

Carver, C. S., \& Harmon-Jones, E. (2009). Anger is an approach-related affect: Evidence and implications. Psychological Bulletin, 135(2), 183-204.

Curtin, S. (2010). Managing the wildlife tourism experience: The importance of tour leaders, International Journal of Tourism Research, 12, 219-236.

Deighton, J., \& Kornfeld, L. (2009). Interactivity's unanticipated consequences for marketers and marketing. Journal of Interactive Marketing, 23(1), 4-10. 
Denegri-Knott, J., Zwick, D., \& Schroeder, J. E. (2006). Mapping consumer power: an integrative framework for marketing and consumer research, European Journal of Marketing, 40(9/10), 950-971.

Deszczyński, B. (2017). Word-of-mouth in social media: The case of Polish tourist industry. International Journal of Management and Economics, 53(4), 93-114.

Eisenhardt, K. M. (1989). Making fast strategic decisions in high-velocity environments. Academy of Management Journal, 32(3), 543-576.

Elkington, J. (2018). 25 Years Ago, I Coined the Phrase "Triple Bottom Line." Here's Why It's Time to Rethink It, Harvard Business Review, 25 June 2018.

Fischer, A., Halperin, E., Canetti, D., \& Jasini, A. (2018). Why we hate. Emotion Review, 10(4), 309-320.

Fiss, P. C. (2013). Case studies and the configurational analysis of organizational phenomena. In D. Byrne (Ed.), The SAGE Handbook of Case-Based Methods (pp. 415431). Sage.

Fournier, S., \& Avery, J. (2011). The uninvited brand. Business Horizon, 54, 193-207.

Funches, V. (2011). The consumer anger phenomena: Causes and consequences. Journal of Services Marketing, 25(6), 420-428.

Gershoff, A., Mukherjee, A., \& Mukhopadhyay, A. (2007). Few ways to love, but many ways to hate: Attribute ambiguity and the positivity effect in agent evaluation. Journal of Consumer Research, 33(4), 499-505.

Glavas, C., Pike, S., \& Mathews, S. (2014). Internet-enabled tourism entrepreneurs. International entrepreneurial values elicited through repertory test and laddering analysis, International Journal of Tourism Research, 16, 44-55.

Gnoth, J. (1997). Tourism motivation and expectation formation. Annals of Tourism Research, 24(2), 283-304. 
Grégoire, Y., Tripp, T. M., \& Legoux, R. (2009). When customer love turns into lasting hate: the effects of relationship strength and time on customer revenge and avoidance. Journal of Marketing, 73 (November), 18-32.

Grégoire, Y., \& Fisher, R. J. (2008). Customer betrayal and retaliation: when your best customers become your worst enemies. Journal of the Academy of Marketing Science, 36(2), 247-261.

Gretzel, U., Fesenmaier, D. R., \& O’Leary, J. R. (2006). The transformation of consumer behavior. In D. Buhalis and C. Costa (Eds.), Tourism Business Frontiers: Consumers, Products and Industry (pp. 9-18). Oxford: Elsevier.

Halperin, E., Russell, A.G., Dweck, C.S., \& Gross, J. J. (2011). Anger, hatred, and the quest for peace: Anger can be constructive in the absence of hatred. Journal of Conflict Resolution, 55(2), 274-291.

Halperin, E., \& Gross, J. M. (2010). Intergroup anger in intractable conflict: Long-term sentiments predict anger responses during the Gaza War. Group Processes \& Intergroup Relations, 14(4), 477-488.

Hjalager, A. M. (2001). Quality in tourism through the empowerment of tourists. Managing Service Quality: An International Journal, 11(4), 287-296.

Huang, Y., Scott, N., Ding P., \& Cheng, D. (2012). Impression of Liusanjie: Effect of mood on experience and satisfaction. International Journal of Tourism Research, 14, 91-102.

Jalonen, H. (2014). Negative emotions in social media as a managerial challenge. www.academia.edu/9489776/Negative_emotions_in_social_media_as_a_managerial_ch allenge (Accessed 25th October 2016).

Jani, D., \& Han, H. (2013). Personality, social comparison, consumption emotions, satisfaction, and behavioral intentions: How do these and other factors relate in a hotel 
setting? International Journal of Contemporary Hospitality Management, 25(7), 970993.

Jarvenpaa, S. L., \& Tuunainen, V. K. (2013). How Finnair socialized customers for service co-creation with social media. MIS Quarterly Executive, 12(3), 125-136.

Krippendorff, K. (2004). Content analysis: An introduction to its methodology. Thousand Oaks, London, New Delhi: Sage Publications.

Ku, E. C. S. (2014). Distributed fascinating knowledge over an online travel community, International Journal of Tourism Research, 16, 33-43.

Kuppens, P., Van Mechelen, I., Smits, D. J. M., \& De Boeck, P. (2003). The appraisal basis of anger: Specificity, necessity, and sufficiency of components. Emotion, 3(3), 254-269.

Labrecque, L. I., vor dem Esche, J., Mathwick, C., Novak, T. P., \& Hofacker, C. F. (2013). Consumer power: Evolution in the digital age. Journal of Interactive Marketing, 27, 257269.

Larsen, S., Brun, W., \& Øgaard, T. (2009). What tourists worry about: Construction of a scale measuring tourist worries. Tourism Management, 30(2), 260-265.

Leung, D., Law, R. van Hoof, H., \& Buhalis, D. (2013). Social media in tourism and hospitality: a literature review. Journal of Travel \& Tourism Marketing, 30(1-2), 3-22.

Lin, S. W. (2017). Identifying the critical success factors and an optimal solution for mobile technology adoption in travel agencies. International Journal of Tourism Research, 19, 127-144.

Litvin, S., Goldsmith, R., \& Pan, B. (2008). Electronic word-of-mouth in hospitality and tourism management. Tourism Management, 29(3), 458-468.

Miles, M. B., \& Huberman, A. M. (1994). Qualitative data analysis (2nd ed.). Thousand Oaks, CA: Sage. 
Moro, S., \& Rita, P. (2018). Brand strategies in social media in hospitality and tourism. International Journal of Contemporary Hospitality Management, 30(1), 343364.

Munzel, A., \& Kunz, W. (2013). Sharing experiences via social media as integral part of service experience. In J. Kandampully (Ed.), Customer experience management: enhancing experience and value through service management. Kendal Hunt Publisher.

Neuhofer, B., Buhalis, D., \& Ladkin, A. (2014). A typology of technology-enhanced tourism experiences. International Journal of Tourism Research, 16(4), 340-350.

Niininen, O., Buhalis, D., \& March, R. (2007). Customer empowerment in tourism through consumer centric marketing (CCM). Qualitative Market Research: An International Journal, 10(3), 265-281.

Nusair, K., Bilgihan, A., \& Okumus, F. (2013). The role of online social network travel websites in creating social interaction for Gen Y Travelers. International Journal of Tourism Research, 15, 458-472.

Okazaki, S., Andreu L., \& Campo, S. (2017). Knowledge sharing among tourists via social media: A comparison between Facebook and TripAdvisor. International Journal of Tourism Research, 19, 107-119.

Önder, I. (2017). Forecasting tourism demand with Google Trends: Accuracy comparison of countries versus cities. International Journal of Tourism Research, 19, 648-660.

Oriade, A, \& Robinson, P. (2019). Prosuming tourist information: Asking questions on TripAdvisor. International Journal of Tourism Research, 21, 134-143.

Pascual-Leone, A., Gilles, P., Singh, T., \& Andreescu, C. A. (2013). Problem anger in psychotherapy: An emotion-focused perspective on hate, rage, and rejecting anger. Journal of Contemporary Psychotherapy, 43(2), 83-92. 
Pavesi, A., Gartner, W., \& Denizci-Guillet, B. (2016). The effects of a negative travel experience on tourists' decisional behavior. International Journal of Tourism Research, $18,423-433$.

Pellow, D., Schnaiberg, A., \& Weinberg, A. (1995). Pragmatic Corporate Cultures, The Journal of Corporate Environmental Strategy and Practice, 12, 95-110.

Pettigrew, A. M. (1990). Longitudinal field research on change: Theory and practice. Organization Science, 1(3), 267-292.

Pfeffer, J., Zorbach, T., \& Carley, K. M. (2014). Understanding online firestorms: Negative word-of-mouth dynamics in social media networks. Journal of Marketing Communications, 20, 117-128.

Pires, G. D., Stanton, J., \& Rita, P. (2006). The internet, consumer empowerment and marketing strategies. European Journal of Marketing, 40(9-10), 936-949.

Rauschnabel, P. A., Kammerlander, N., \& Ivens, B. S. (2016). Collaborative brand attacks in social media: Exploring the antecedents, characteristics, and consequences of a new form of brand crises. Journal of Marketing Theory and Practice, 24(4), 381-410.

Rihova, I., Buhalis, D., Moital, M., \& Gouthro, M-B. (2015). Conceptualising customer-tocustomer value co-creation in tourism. International Journal of Tourism Research, 17(4), 356-363.

Romani, S., Grappi, S., \& Bagozzi, R. P. (2013). My anger is your gain, my contempt your loss: explaining consumer responses to corporate wrongdoing. Psychology \& Marketing, 30(12), 1029-1042.

Rosa, P., Carvalhinho, L., \& Soares, J. (2018). Developing a destination image through the perceptions of stakeholders: A case study. International Journal of Tourism Research, 20(1), 60-71.

Royzman, E. B., McCauley, C., \& Rosin, P. (2005). From Plato to Putnam: Four ways to 
think about hate. In The psychology of hate, ed. Robert J. Sternberg, 3-36. Washington, DC: American Psychological Association.

Rydén, P., Ringberg, T., \& Wilke, R. (2015). How managers's shared mental models of business-customer interactions create different sensemaking of social media. Journal of Interactive Marketing, 31, 1-16.

Schreier, M. (2012). Qualitative content analysis in practice. London, Thousand Oaks, New Delhi, Singapore: Sage Publications.

Senders, A., Govers, R., \& Neuts, B. (2013). Social media affecting tour operators' customer loyalty. Journal of Travel \& Tourism Marketing, 30(1-2), 41-57.

Shankar, A., Cherrier, H., \& Canniford, R. (2006). Consumer empowerment: A foucauldian interpretation. European Journal of Marketing, 40(9/10), 1013-1030.

Sigala, M. (2012). Exploiting Web 2.0 for new service development: Findings and implications from the Greek tourism industry. International Journal of Tourism Research, 14, 551-566.

Slovic, P., Finucane, M. L., Peters, E., \& MacGregor, D. G. (2004). Risk as analysis and risk as feelings: Some thoughts about affect, reason, risk, and rationality. Risk Analysis, 24, 311-322.

So, K. K. F., Wu, L., Xiong, L., \& King, C. (2017). Brand management in the era of social media: Social visibility of consumption and customer brand identification. Journal of Travel Research, 57(6), 727-742.

Su, L., Hsu, M. K., \& Marshall, K. P. (2014). Understanding the relationship of service fairness, emotions, trust, and tourist behavioral intentions at a city destination in China. Journal of Travel \& Tourism Marketing, 31(8), 1018-1038.

Truong, Y., \& Simmons, G. (2010). Perceived intrusiveness in digital advertising: Strategic marketing implications. Journal of Strategic Marketing, 18(3), 239-256. 
Tsaur, S., Chiu, Y., \& Wang, C. (2007). The visitors' behavioral consequences of experiential marketing. Journal of Travel \& Tourism Marketing, 21(1), 47-64.

Tyrrell, B., \& Woods, R. (2004). E-Complaint. Journal of Travel \& Tourism Marketing, 17(2-3), 183-190.

Wang, Y., Weaver, D. B, \& Kwek, A. (2016). Beyond the mass tourism stereotype: Power and empowerment in Chinese tour packages. Journal of Travel Research, 55(6), $724-737$.

Wee, C. H. (2017). Emerging trends in tourism: Opportunities, challenges and implications. Journal of Tourism \& Hospitality, 6(318). https://doi.org/10.4172/2167-0269.1000318

Wright, L.T., Newman, A., \& Dennis, C. (2006) Enhancing consumer empowerment, European Journal of Marketing, 40(9/10), 925-935.

Zhang, J. (2012). Tourist attraction development in Denmark and its impact on regions. Proceeding of the 6th World Conference for Graduate Research in Tourism, Hospitality and Leisure, 1126-1145.

Zhong, L., Leung, D., Law, R., Wu, B., \& Shao, J. (2014). An application of the capability maturity model for evaluating attraction websites in mainland China. International Journal of Tourism Research, 16(5), 429-440.

Zimmerman, C., Chen, Y., Hart, D., \& Vatrapu, R. (2014). Marius, the giraffe. A comparative informatics case study of linguistic features of the social media discourse. Proceeding of the 5th ACM Int. Conference on Collaboration Across Boundaries: Culture, Distance, \& Technology, 131-140. 